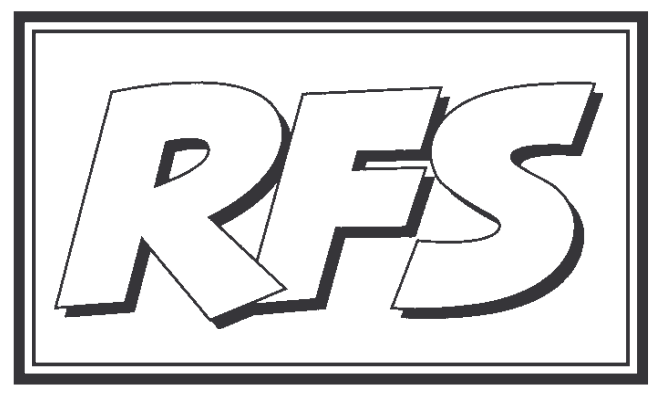

Revista de Fomento Social, 61 (2006), 87-105

\title{
Buscar la paz en un mundo violento
}

\footnotetext{
— Secretariado de la Compañía de Jesús para la Justicia Social -
}

\section{Nota del Consejo de Redacción}

El Secretariado para la Justicia Social es el organismo de la Com pañía de Jesús que inspira y coordina la reflexión y la acción social del apostolado de los jesuitas. Nuestra RFS se inscribe precisamente en ese ấrea de trabajo. Con la anuencia y satisfacción de quienes lo han elaborado, ofrecemos a nuestros lectores este texto que a nosotros nos ha interesado vivamente. Se trata del documento final del "Taller Internacional sobre Violencia y Guerra: Intereses Culturales y Económicos", organizado por dicho Secretariado ${ }^{1}$. El taller tuvo

1 Véase Promotio Iustitiae, $\mathrm{n}^{\mathrm{o}}$ 89, 2005/4, pp. 17-26. En dicho número de PJ se encontrarán otra serie de documentos relacionados con el evento. De especial interés es la presentación del número (con una información detallada acerca del taller) a cargo de Fernando Franco SJ, Secretario de la Compañía de Jesús para la Justicia Social. El texto original fue publicado en 
lugar en Roma del 4 al 17 de septiembre de 2005. A pesar de las referencias específicas y de la perspectiva particular de la "familia ignaciana", creemos que el texto interesará a nuestros lectores habi tuales e incluso que, en cierta manera, puede ser una "hoja de ruta" para personas y colectivos que buscan caminos para la superación de conflictos y el establecimiento de una paz duradera. Estas son las mismas preocupaciones que movieron a los autores de esta reflexión. Sólo hemos omitidos las recomendaciones finales, de carácter más institucional e interno para la Compañía de Jesús.

\section{Dónde estamos y qué hemos hecho}

1. Somos un grupo global y diverso de 45 personas, jesuitas, colegas reli giosos y laicos, hombres y mujeres, que hemos participado en un encuentro de dos semanas cerca de Roma para discernir y reflexionar sobre la respuesta posible de la Familia Ignaciana y sus obras apostólicas a las realidades de la guerra, la violencia y el reto hacia una paz duradera en nuestro mundo actual. En efecto, sentimos que las complejas realidades de violencia y los movimientos emergentes por la paz requieren que nos centremos en nuestro papel y compromiso respecto a la violencia y a la paz, puesto que somos parte de una organización global que tiene ya una base de conocimientos intelectuales, está en contacto con las situaciones del pueblo donde los efectos de la violencia son directamente tangibles y tiene la capacidad de organizar apoyos y de influir sobre la toma de decisiones políticas.

2. Queremos compartir con el P. General, con toda la Compañía de Jesús y con la Familia Ignaciana las ideas a las que hemos llegado, las preocu paciones que tenemos y las conclusiones que hemos sacado. Queremos destacar algunos de los nuevos retos que vemos hoy con respecto a la violencia, la guerra, la transformación de los conflictos y la paz duradera. Hemos descubierto nuevos retos y nuevas posibilidades en nuestro mun do. En este mundo en proceso de globalización, las caras de la violencia y de la guerra han cambiado en complejidad, intensidad, interrelación y riesgo. En respuesta a esas nuevas formas de violencia han surgido nuevas instituciones internacionales y también nuevos movimientos e iniciativas

inglés; la traducción castellana había sido preparada por un equipo de Entreculturas, con la colaboración especial de Carmen Pita e Isabel Paya. La publicación citada puede consultarse en www.sjweb.info/sjs. 
por la paz que nos llaman a articular nuestros propios compromisos. No pretendemos proponer "soluciones" a estos retos. Más bien proponemos entrar en un proceso de discernimiento espiritual compartido que nos permitirá a todos nosotros comprometernos en situaciones de cambio continuo al servicio de aquellos que más sufren los efectos de la violencia y la ausencia de una paz duradera.

3. La experiencia del discernimiento compartido durante este encuentro ha sido una iniciativa fructífera y creativa. En nuestro camino para descu brir la acción de Dios en nosotros y su deseo para nuestro mundo y para su pueblo, hemos compartido recursos espirituales e ignacianos en la oración en común y en la liturgia, hemos escuchado con atención y agradecimiento experiencias de unos y otros, historias, preocupaciones y puntos de vista, y hemos descubierto cómo emerge la creatividad en nuestras relaciones mutuas en medio de nuestra gran diversidad. En todo ello hemos sentido la consolación de la presencia y la gracia de Dios, que nos da la fuerza para dedicarnos concretamente al servicio de la paz, cada uno de nosotros en sus propias circunstancias específicas. Hemos experimentado cómo este proceso de discernimiento espiritual que afecta a todo nuestro ser humano, -afectos, conocimiento, voluntad-, enriquece nuestra comprensión y la acción en favor de la construcción de una paz sostenible y, de hecho, constituye un método de llegar a una paz duradera en medio de violentos conflictos. Animamos a que este enfoque, en el que la reflexión sobre violencia y paz se enriquece con el diálogo compartido y la oración, sea promovido en la Familia Ignaciana. En efecto, por medio de este instrumento podemos hacer uso de nuestros conocimientos corporativos, nuestra presencia entre el pueblo y nuestra capacidad internacional para influir, defender y actuar.

4. Al experimentar este proceso de discernimiento compartido, y en lo más profundo de nuestra consolación, hemos sentido la necesidad del poder regenerativo del perdón y la reconciliación, que nos une a todos en una comunidad de paz y por la paz. Hemos tocado nuestras historias per sonales de fallos y de pecado, y también las de nuestras instituciones, de la Compañía de Jesús y de la Familia Ignaciana. Hemos recordado nuestras omisiones cuando no nos hemos atrevido a enfrentarnos a la violencia, el apoyo que hemos dado a veces a la violencia, nuestra propia violencia hacia los demás, nuestra cobardía y nuestra falta de sensibilidad para escuchar el grito de los que sufren. A lo largo del encuentro hemos experimentado también nuestras limitaciones y heridas, que pueden volvernos sordos a las historias y opiniones de otros, que puedan producir mecanismos de defensa 
o el temor a entrar en confrontaciones creativas y conflictos, que puedan despertar en nosotros violencia frente a los demás, y que puedan hacernos ciegos para apreciar en los otros el rostro de un Dios de paz y compasión. Por tanto, cuando presentamos este documento, sabemos que tenemos que ser humildes: somos parte integrante de las historias de violencia y paz de este mundo. Con este espíritu de humildad optamos por servir a Dios y a la humanidad en su proyecto de paz duradera.

\section{Nuevos desafíos de conflicto y violencia hoy}

5. La guerra, el conflicto armado y la violencia se encuentran entre los aspectos más trágicos del escenario humano. Los conflictos armados actua les tienen algunos aspectos significativamente nuevos que reclaman nuevas respuestas.

\section{Conflictos de Identidad}

6. Muchas de las guerras actuales están impulsadas por conflictos basados en la identidad cultural y tienen dimensiones nacionalistas, étnicas y a veces religiosas. El genocidio de Ruanda y el violento conflicto en la región de los Grandes Lagos ilustran trágicamente cómo los conflictos de grupo basados en la identidad pueden provocar inmensos daños humanos. La antigua Yugoslavia y Sudán son otros tantos ejemplos de tragedias motivadas por tales conflictos de identidad. La religión, a veces, juega un papel significativo en los conflictos contemporáneos: los fundamentalismos religiosos son factores del conflicto en Oriente Medio, zonas de África, Asia, y en los conflictos terroristas-antiterroristas, tan destructivos hoy en día. Las dimensiones religiosas de los conflictos contemporáneos han llevado a algunos analistas a la conclusión de que la religión se está convirtiendo en la fuente primaria de guerra y confrontación en el mundo posterior a la guerra fría. Aunque creemos que es un error el atribuir a un sólo factor la causa principal de todos los conflictos actuales, el papel jugado por las comunidades religiosas en los conflictos contemporáneos suscita con toda seguridad un reto pode roso para que estas comunidades puedan convertirse en agentes de paz y reconciliación allí donde reine la guerra y la violencia.

7. La identidad necesita definirse de manera inclusiva evitando el en frentamiento y la exclusión que niegan la humanidad misma de los demás, y por este mismo hecho ejerce la violencia. El reconocimiento del otro 
como diferente es quizá el examen clave sobre si se es capaz de reconocer la dignidad inherente a todos los seres humanos. Los cristianos creemos que cada ser humano ha sido creado a imagen de Dios y por tanto tiene una dignidad que exige respeto y atención. Otras tradiciones seculares y religiosas tienen percepciones similares. Frente a los conflictos del siglo XX, estas percepciones han conducido al nacimiento de una ética de derechos humanos universalista que nos llama a salir de nuestros límites comunales cerrados hacia fronteras abiertas de solidaridad humana entre las diversas comunidades de nuestro mundo. Hoy nos enfrentamos al desafío de ayudar a construir la paz haciendo avanzar más este espíritu en colaboración con todos los que están trabajando por la protección de la dignidad humana en comunidades inclusivas.

8. Todo esto nos llama a un diálogo interreligioso profundo, que es con dición para una paz duradera en medio de la diversidad religiosa. Se han propuesto varios modelos teológicos para llevar adelante este diálogo. Necesitan de una mayor reflexión a la luz de nuevas experiencias. En nuestro taller, hemos experimentado la necesidad de estar abiertos al compromiso con otras denominaciones cristianas, otras tradiciones religiosas aparte del cristianismo (incluyendo las religiones de los pueblos indígenas) y personas que no profesan religión alguna. Tal apertura al compromiso es en sí misma el comienzo de la paz. Por tanto podemos decir hoy que "el diálogo es el nuevo nombre de la paz".

\section{Globalización, Conflicto y Justicia}

9. Muchos de los conflictos armados de hoy están sustentados por las desigualdades de poder económico y político. La globalización orientada al mercado lleva a los pueblos beneficios y cargas muy desiguales: suele beneficiar a una clase, etnia o grupo religioso dentro de un país o región en detrimento de otros. Los conflictos en Chad, Colombia y zonas de la India, que nuestro taller analizó con cierta profundidad, tienen importantes raí ces en las desigualdades de poder político y económico. Algunas de estas luchas, que podrían parecer a primera vista conflictos de etnia o religión, están estimuladas por la disputa sobre beneficios económicos y participación política. De manera similar, la dependencia económica del petróleo en los países desarrollados es un aspecto central de los recientes conflictos que aún continúan en Irak. Es más, las políticas de los poderosos países desarfo llados, de instituciones financieras internacionales como el Fondo Monetario 
Internacional y el Banco Mundial, y de las empresas multinacionales, juegan también un papel importante en la creación de condiciones que alientan tales conflictos, o en ocasiones ayudan a aliviarlos. El afán de conservar privilegios económicos puede conducir a grupos más acomodados a la acción violenta para excluirse de aquellos que poseen mucho menos. También, cuando las personas se sienten tan excluidas económica o culturalmente que no tienen nada que perder, la lucha armada e incluso el terrorismo pueden presentarse como el único camino capaz de mejorar sus vidas. La guerra y el conflicto armado, sin embargo, casi siempre disminuyen el bienestar económico de aquellos a quienes afecta.

10. La justicia auténtica ha sido siempre una condición previa importante para la paz, y más en nuestros tiempos. La justicia exige que cada uno sea capaz de participar en la vida económica, cultural y política de la comunidad, en la forma básica que él, o ella, necesite para ser respetado como persona. Lo opuesto a esta participación puede llamarse marginación -la exclusión de poder producir o compartir dentro del bien común de la comunidad. Puede tomar la forma política de concentración de poder en las manos de un partido único o una élite gobernante. Las personas pueden ser marginadas por su raza, cultura, religión o género, llegando en casos extremos a los horrores del genocidio o la limpieza étnica. Formas de exclusión menos dramáticas pero también profundamente injustas, son las derivadas de políticas econé micas y estructuras que causan pobreza o carencia de educación, asistencia sanitaria y empleo. Las mujeres y las niñas sufren también de una exclusión mayor que los varones. Nuestros esfuerzos para construir la paz están unidos a superar todas estas formas de exclusión de los pobres y vulnerables, tanto dentro de las naciones como globalmente.

11. Este concepto de participación como algo esencial a la justicia tiene consecuencias importantes en nuestra forma de juzgar un buen gobierno, la responsabilidad y el papel de la sociedad civil a diversos niveles. La co rrupción burocrática en el gobierno es otra forma de violencia que quita la comida al pobre y abusa del cargo público para el enriquecimiento privado. Los grupos locales, como sindicatos y organizaciones comunitarias, así como las ONGs nacionales e internacionales pueden ayudar en exigir a los gobiernos que se hagan responsables del bienestar de las personas. Este es un modo de servir a la causa de la paz. De la misma manera, las organizacio nes regionales y nacionales pueden también exigir responsabilidades a las instituciones internacionales y globales. Por ejemplo, redes que se centran en temas de medio ambiente, derechos humanos, legislación humanitaria y 
la dignidad de la mujer, pueden conferir legitimidad a gobiernos y empresas multinacionales o pueden retirársela. Es esta una forma de "poder suave" que podemos utilizar a favor de la justicia y de la paz.

\section{El reto del desplazamiento y la migración}

12. Las guerras recientes han producido más de treinta millones de re fugiados y otros desplazados, la mayoría mujeres y niños. La comunidad internacional ha dado algunos pasos vacilantes para responder al tema de los refugiados que han tenido que abandonar sus casas por persecución. Sin embargo, los que han sido forzados más allá de sus fronteras por la guerra o los desplazados internamente dentro de su propio país son olvidados con frecuencia. La restauración de la justicia exige que se permita a estas perse nas el regresar con plena participación como ciudadanos de sus países de origen o bien convertirse en ciudadanos activos de los países de acogida. La destrucción de los medios de subsistencia que garantizan la supervivencia económica se ha convertido también en una fuente importante de migración, y muchos países son cada vez más reacios a recibir a tales inmigrantes. De hecho, la resistencia a la inmigración y el rechazo a reconocer su existen cia misma, son fuente de actitudes negativas hacia los que son diferentes, conduciendo a nuevas formas de conflicto. El trabajo del Servicio Jesuita a Refugiados hace que estos desafíos nos afecten especialmente.

\section{Retos medioambientales}

13. En muchos de los conflictos armados actuales, el control sobre los recursos naturales, como el petróleo, el carbón y otros minerales, es un factor clave. La lucha por el agua se está convirtiendo también en una seria amenaza para la paz. En los años venideros, las guerras medioambientales, la lucha por el control de recursos, y la injusticia se convertirán proba blemente en temas todavía más importantes. Existe un claro nexo entre degradación medioambiental, pobreza e injusticia. Cuando los conflictos potenciales van acompañados por el desarrollo de armas de destrucción masiva tecnológicamente avanzadas (nucleares, químicas o biológicas), aumenta aún más la amenaza de guerra al medioambiente. Una valoración más profunda de la relación entre justicia e integridad de la creación, la preocupación por las generaciones futuras, el significado de la biodiversidad y el aspecto destructivo del medioambiente que la guerra contemporánea 
conlleva son nuevos desafíos en los conflictos que vemos hoy en torno a nosotros $^{2}$.

\section{El reto de la no violencia}

14. Quizás el reto más fundamental al que nos enfrentamos al enfocar la realidad del conflicto, es si el uso de la violencia puede estar justificado moralmente. Gandhi y Martin Luther King entre otros, han sido ejemplos estimulantes del poder de las respuestas no violentas ante la opresión y la injusticia. El Concilio Vaticano II puso un énfasis innovador en la no violen$\mathrm{cia}^{3}$, y muchos católicos se han ido convenciendo cada vez más de que el recurso a la fuerza militar nunca es apropiado como estrategia para cam bios sociopolíticos. Al mismo tiempo, y aunque con dificultad, habría que admitir que la intervención militar humanitaria, para proteger a la población inocente de una grave violencia, como fue el genocidio de Ruanda en 1994, puede estar justificada. La postura que justifica el uso de la fuerza militar en circunstancias estrictamente definidas y excepcionales, y siempre como último recurso, sigue siendo parte de las tradiciones de la ética católica y de las leyes internacionales. Es evidente que los seguidores de Cristo tienen un compromiso fundamental en la búsqueda de la justicia de forma no violenta. Por tanto, los cristianos nunca pueden recurrir al uso de la fuerza sin graves vacilaciones. La paz es nuestro compromiso primero y la no violencia es el camino hacia una paz justa, a no ser en casos excepcionales, como la protección de un pueblo ante el genocidio, la limpieza étnica u otras graves injusticias y violaciones de derechos humanos. Una de las principales tareas intelectuales a que nos enfrentamos en el futuro, será el ponderar cómo llevar a cabo este compromiso en diferentes circunstancias.

15. Este compromiso con la no violencia da respaldo adicional a la creciente convicción de que en el mundo actual, la soberanía nacional no puede considerarse por más tiempo como una especie de valor absoluto en el mundo interdependiente y globalizado de hoy. Tanto los Estatutos de Naciones Unidas como el magisterio reciente de la Iglesia afirman que la respuesta internacional a graves formas de opresión y violación de los derechos hu -

${ }^{2}$ Nuestro taller tuvo lugar mientras evolucionaba la catástrofe de Nueva Orleáns, y cuando el debate sobre los Objetivos del Milenio de la ONU y sobre los protocolos de Kyoto eran noticias candentes.

${ }^{3}$ Concilio Vaticano II, Gaudium et Spes, n. 78. 
manos, como el genocidio o la limpieza étnica, tiene que ser multilateral, no unilateral. La convicción religiosa de que todos formamos parte de una familia humana al amparo de Dios significa que las fronteras de las naciones-estado no determinan los límites de nuestra responsabilidad moral. Esto tiene impli caciones importantes no sólo para los asuntos militares, sino también en el campo del uso de los recursos, interacción económica, incidenciadvocacy) internacional y nuestra valoración del impacto de las fuerzas globales, por ejemplo los medios de comunicación, sobre la cultura local.

\section{La reconciliación como reto}

16. Cada vez está más claro que, en muchas ocasiones, la búsqueda de una paz duradera en el período subsiguiente a un conflicto puede requerir formas innovadoras de reconciliación e incluso el perdón. La reconciliación no puede tener lugar mientras continúe la injusticia. Por tanto debe cesar la injusticia para poder instaurar una paz duradera. Pero también es verdad que la justicia no es sinónimo de venganza. La justicia restauradora recons truye comunidades que han sido fracturadas por el conflicto. Esa justicia restauradora es en si misma una forma de reconciliación, y puede invitar al perdón del autor de la injusticia y la violencia, abriendo nuevos caminos a una paz capaz de perdurar. Así, el Papa Juan Pablo II observó que no puede haber paz sin justicia, ni justicia sin perdón. Perdonar no significa olvidar. En efecto, la verdadera reconciliación no puede producirse si los daños pa sados están ocultos a la vista por la impunidad que gozan sus autores. Pero el perdón puede venir como regalo y gracia cuando un nuevo futuro aparece a la vista, un futuro vivido en justicia y verdad. En medio del trabajo que hacemos para suscitar una paz duradera en nuestros ministerios, estamos llamados a descubrir caminos nuevos y efectivos que promuevan esa justicia restaurativa y la reconciliación.

\section{Retos espirituales y teológicos}

17. A la luz de estos nuevos desafíos de violencia y de construcción de paz, los participantes en nuestro taller se sienten llamados a encontrar un modo nuevo de enfocar nuestra espiritualidad y teología para que nos ayuden a discernir el camino a recorrer. No podemos proponer aquí soluciones definitivas, más bien invitamos a los Jesuitas y a nuestros colaboradores, incluyendo a aquellos que profesan otras tradiciones religiosas, a unirse en un proceso de discernimiento. 
18. Nuestra respuesta a las realidades de violencia y paz está firmemente unida a la forma en que vivimos nuestra relación con Dios. Nuestra fe, espi ritualidad y teología son asuntos públicos, no privados. Abren una imagen de nuestras relaciones mutuas y con Dios. Por tanto, espiritualidad y teo logía ejercen un poderoso impacto sobre la vida social y, específicamente, sobre nuestro acercamiento a los demás por medio de relaciones pacíficas o violentas.

19. En situaciones de violencia, los cristianos están llamados a vivir la proclamación que hizo Jesús del Reino de Dios como reino de paz. Es esta una llamada a rechazar la violencia, una invitación al perdón y a la reconcilia ción y una llamada a reconstruir comunidades rotas. En muchas ocasiones, Jesús exhortó a sus discípulos a ser constructores de paz, a amar al pró jimo (incluso al enemigo) y a seguirle tomando la cruz. Los cristianos han fracasado muchas veces en vivir esta llamada a construir la paz. La cruz es malinterpretada si se ve simplemente como una exhortación a soportar la injusticia o el dolor. La cruz nos desafía a seguir a Jesús siendo testigos del Reino de Dios, sin importar lo que cueste. La crucifixión de Jesús es también un símbolo poderoso de la solidaridad de Dios y de su identificación con todos los que sufren y se enfrentan a la muerte, incluyendo a aquellos que sufren y mueren en conflictos. De esta manera, la cruz nos llama a servir a aquellos que sufren injusticia y violencia, incluso cuando nos cueste. Nues tra fe en la resurrección nos permite confiar que la paz es posible incluso cuando nos enfrentamos a conflictos no resueltos. Esta confianza es capaz de sostener la esperanza que nos otorga una pasión por lo posible, la confianza profunda en que una resistencia paciente y valerosa en la lucha por la paz terminará siendo victoriosa.

20. La realidad de la violencia desafía también nuestra manera de entender la Iglesia. La comunidad cristiana debería ser un reflejo de la acción de Dios por la paz y contra la violencia en nuestro mundo. En nuestro taller hemos oído muchas historias de la Iglesia en acción como comunidad de paz y reconciliación. Pero desgraciadamente, hemos oído también historias de cómo la comunidad cristiana no ha intervenido o cuando ha intervenido lo ha hecho de forma que ha provocado violencia. Tales experiencias nos invitan a respuestas radicales, críticas y creativas que permitan a la Iglesia convertirse en la comunidad de reconciliación a que está llamada por el Es píritu. Sólo en diálogo auténtico y en unión con personas de otras creencias y tradiciones puede la Iglesia ejercer su función pacificadora. El reto central de nuestro tiempo es profundizar en una espiritualidad y teología que nos 
puedan conducir a un trabajo más efectivo por la paz, en colaboración con todos los hombres de buena voluntad.

\section{Nuevos movimientos por la paz hoy}

21. Durante nuestro encuentro, hemos sido más conscientes de la existencia de iniciativas de paz y movimientos por la paz en todo el mundo. Han surgi do de organizaciones de la sociedad civil ${ }^{4}$, incluyendo un número cada vez mayor de iniciativas del pueblo, ONGs nacionales e internacionales, iglesias e instituciones educativas, organismos gubernamentales y organizaciones multilaterales. Hemos experimentado la fuerza creativa de estos movimien tos. Nos damos cuenta de que nuestro contexto mundial globalizado, que ha generado nuevos tipos de guerra y violencia, proporciona también nuevas oportunidades e iniciativas por la paz alimentando nuestra esperanza de que es posible un mundo pacífico y justo.

\section{Movimientos populares}

22. En los procesos de pacificación y construcción de paz participan vale rosa y creativamente nuevos actores y movimientos. Queremos destacar el papel de los grupos y comunidades del pueblo, estudiantes universitarios, mujeres e indígenas. Somos testigos del papel cada vez más importante que representan las comunidades locales y organizaciones del pueblo como pa cificadores, articulando en sus iniciativas elementos de diálogo, desarrollo, resistencia y reconciliación. Los movimientos de mujeres son también un agente esencial para la construcción de una paz más amplia y duradera y para hacer posible vías de reconciliación, como en los casos de Zambia, India e Indonesia. Los movimientos indígenas y campesinos contribuyen desde sus culturas locales a la resolución del conflicto y a la construcción de la paz, compartiendo con todos nosotros sus tradiciones y prácticas, como en los casos de Chiapas en México y grupos tribales de la India. Algunos de estos nuevos actores necesitan ser fortalecidos (por medio de actividades de concientización, organización, estrategia y trabajo en red) para así poder

4 Un ejemplo de este número creciente de iniciativas de paz es la reciente publicaciónPeople Building Peace II -Successful Stories of Civil Societ)(p. van Tongeren et al., Eds., 2005, Reinner Publishers), que reúne más de 60 experiencias diferentes de grupos de la sociedad civil y organizaciones de todo el mundo. 
jugar un papel más efectivo en el proceso, mediante una participación más amplia en todas las fases de la construcción de paz.

\section{Nuevas redes}

23. La globalización favorece algunas de las guerras y conflictos violentos en curso. Ofrece también mayores oportunidades para el trabajo en red al servicio de la paz. El reto de la fragmentación e impotencia común en todas las situaciones de conflicto, así como la complejidad internacional de los conflictos contemporáneos nos ha mostrado la importancia de respaldar algunos de los esfuerzos hechos por las organizaciones supranacionales y de construir redes de compañerismo y solidaridad entre los pacificadores. Los grupos y organizaciones de la sociedad civil pueden trabajar juntos, tanto en el ámbito local como internacional, facilitando así la búsqueda de soluciones y alternativas, sobre todo para los grupos afectados con los que estamos en contacto.

24. En primer lugar, los organismos internacionales como Naciones Uni das, la Unión Europea, y organizaciones regionales como la Organización de Estados Americanos y la Unión Africana están representando papeles cada vez más constructivos en el proceso de paz. Otros acuerdos globales, como el acuerdo de Kyoto e instituciones como el Tribunal Criminal Inter nacional se enfrentan a problemas críticos que están relacionados con una paz sostenible.

25. En segundo lugar, las campañas globales y nacionales, como la cam paña internacional para la prohibición de las minas antipersona y contra la utilización de niños soldado; la red internacional de acción contra la proliferación de armas ligeras; la campaña en favor de derechos humanos básicos de las comunidades Dalit y Adivasi; la campaña a favor de la mujer en la India, pueden influir en los responsables de tomar decisiones y en la opinión pública global, desafiando incluso los relatos bélicos.

26. En tercer lugar, existe un creciente dinamismo de "ciudadanos del mundo" en solidaridad. Constatamos este hecho en el aumento de los grupos transnacionales de incidencia (advocacy) y cabildeo que trabajan en temas como derechos humanos y legislación humanitaria internacional, el avance de la mujer y la protección del medio ambiente. Compartimos experiencias de trabajo en red (como la Red Ignaciana de Solidaridad en Estados Unidos, la Red Africana de Jesuitas SIDA y la Red Internacional Jesuita para el Desarrollo); 
de apoyo solidario y ayuda (como Entreculturas, Alboan, Iniciativa de los Pueblos del Sur de Asia); y de cabildeo e incidenciad(vocacy) en Washington (Oficina de Ministerios Sociales e Internacionales de la Conferencia Jesuita de Estados Unidos), en Bruselas y en otras partes (SJR). Somos conscientes de la necesidad de hacer un cabildeo e incidencia juntos en solidaridad. La incidencia (advocay) es un camino importante en el que la Compañía puede ejercitar una fe que hace justicia y ha de verse como un elemento importante del trabajo por la justicia. Esta incidencia (dvocacy) debe entenderse como un esfuerzo para incidir sobre políticas generales a tres niveles: en estructuras nacionales, gubernamentales y legislativas; en estructuras internacionales y regionales (como la Unión Europea, Naciones Unidas, el Banco Mundial, etc.), y en corporaciones (inversión social responsable).

27. En cuarto lugar, están surgiendo algunas experiencias en el ámbito de la sociedad civil, como el Foro Social Mundial, que sugieren nuevos dinamismos para la construcción de nuestro mundo. Cierto número de jesuitas y colegas laicos han participado en diferentes momentos del Foro y han encontrado nueva inspiración para la paz y la justicia social en su trabajo.

\section{Respuesta a los refugiados y desplazados internos}

28. Hemos constatado también muchas iniciativas en favor de las vícti mas de todo tipo de violencia, por ejemplo, el servicio a los refugiados y a las personas desplazados internamente (IDPs, según las siglas en inglés). Algunos de los desplazamientos masivos de población requieren operaciones de apoyo enormes. El Alto Comisionado de Naciones Unidas para los Refugiados juega un papel destacado, pero existen muchas otras organizaciones involucradas, incluyendo el Servicio Jesuita a Refugiados (SJR) con presencia en más de cincuenta países, y las experiencias representadas en nuestro encuentro: África, Aceh (Indonesia), Europa, Colombia, Venezuela, y el trabajo con emigrantes y refugiados en Ecuador.

\section{Movimientos de derechos humanos, no violencia e interreligiosos}

29. Al hacer frente a la violencia, algunos temas cruciales han ganado importancia: resistencia contra la impunidad mediante diferentes acciones en el campo de derechos humanos y legislación humanitaria internacional. Los métodos no violentos, ejemplificados por Gandhi y Martin Luther King, 
inspiran hoy nuevas iniciativas de paz: comunidades de paz y declaraciones de "neutralidad" en Colombia, zonas de paz en Filipinas e Indonesia. Hay también varias experiencias de diálogo interreligioso nacidas de nuestro activismo por la paz, que han intentado tender puentes entre las partes enfrentadas, como en el caso de Irlanda del Norte, Sudáfrica y Mindanao, en Filipinas.

\section{Procesos de reconciliación}

30. Nos reafirmamos en que una paz sostenible no es posible sin recon ciliación. Se han iniciado numerosos procesos de reconciliación, que van desde las medidas judiciales y comisiones de la verdad a experiencias más localizadas de diálogo entre grupos en conflicto, como en el Sur y Este de África, Ruanda, Irlanda del Norte, País Vasco, Colombia, India y Sri Lanka.

\section{Necesidades críticas}

31. Estas oportunidades que surgen para la paz nos exigen, si es que han de ser duraderas, hacer frente a dos desafíos críticos. En primer lugar, es necesario desarrollar un análisis de los diferentes aspectos del conflicto que reconozcan su complejidad (contextos diferentes requieren respuestas diferentes). Este análisis es necesario para diseñar estrategias más precisas y efectivas para una "agenda para la paz" (esto es: educando, investigando, discerniendo, organizando, haciendo política, protestando, dialogando, resistiendo, rezando). Necesitamos también ampliar nuestro concepto de paz. No es suficiente con plantar cara ante las expresiones de violencia di recta, buscando una paz negativa: la ausencia de guerra. También tenemos que enfrentarnos a las formas de violencia más estructural e indirecta de manera que mujeres y hombres sean capaces de encontrar caminos hacia su desarrollo integral como seres humanos. Por ejemplo, la representación adecuada de mujeres y hombres, el tratamiento igual para todas las razas, el buen gobierno y el desarrollo, son asuntos clave en la construcción de una paz duradera. Además, las diferencias culturales, religiosas, étnicas y de género necesitan espacio, no sólo para su expresión, sino también, particularmente, para la construcción de identidades múltiples e inclusivas en coexistencia fructífera e interactiva.

32. En segundo lugar, observamos que existe una tensión en cuanto a res 
peto y apoyo de aquellos que son víctimas de los conflictos. El esfuerzo de ser la voz de los sectores y países sin voz es ciertamente importante y válido. Pero existe el riesgo de suplantar a esos sectores. No debemos olvidar que las comunidades y los sectores sociales deberían ser sus propios agentes de paz. Es necesario dar el poder de decisión, organización y trabajo en red a los grupos sin voz, para hacerles capaces de hablar por sí mismos.

\section{Nuevas respuestas de los jesuitas y la familia jesuítica}

Compromiso con la paz y nuestras raíces ignacianas

33. En nuestro proceso de discernimiento durante estos días, tras ponderar retos y oportunidades, hemos llegado a hacer nuestra una conclusión clave de la CG 34: "Un reto especial de hoy día es realizar el misterio de salvación y reconciliación de Cristo en un mundo crecientemente dividido por el nivel económico y social, las razas y las etnias, la violencia y la guerra, el pluralismo cultural y religioso. Estas divisiones han de ser un polo de atenón del ministerio sacerdotal del jesuita porque la obra de reconciliación de Cristo derriba el muro de división entre pueblos" (CG 34, d. 6, n.14). Este reto es incluso más fuerte hoy, dado el número de conflictos armados y su carácter globalizado. Hemos escuchado el dolor y el sufrimiento de muchos como resultado de estas guerras y violencia, y a través de estas voces hemos discernido con humildad la llamada de Cristo para unirnos a lo que Dios está haciendo para la reconciliación: "todo eso es la obra de Dios, que nos ha reconciliado con él en Cristo y que a mi me encarg ó la obra de la de la reconciliación" (2 Cor. 5,18$)$. Como los primeros compañeros de la Compañía de Jesús, nos sentimos llamados a trabajar para " reconciliar al separado " (Fórmula del Instituto - 1550, 1).

34. Nuestra experiencia en la construcción de la paz y la reconciliación tiene sus raíces en nuestra espiritualidad ignaciana. Reconociendo nuestra fragilidad y maldad, hemos descubierto que hemos sido perdonados y recon ciliados por el amor incondicional de Dios. Nos sentimos también llamados por el Señor para trabajar con Él al servicio de los demás compartiendo nuestra experiencia más profunda de un Dios Amor, que se compromete Él mismo con los seres humanos en medio de un mundo de violencia, y que Él mismo elige el camino para sellar una alianza con los hombres. Nos hemos sentido invitados por Cristo a caminar en solidaridad con aquellos que es - 
tán crucificados por la violencia y la guerra, manifestándoles la compasión y la ternura incondicionales de nuestro Dios, crucificado de nuevo con las víctimas de hoy. Pero también hemos descubierto que la Resurrección de Cristo está presente entre nosotros, consolándonos y haciéndonos capaces de convertirnos en agentes de paz y reconciliación. Cristo está entre su pueblo, y nos lleva a comprometernos en la construcción de comunidades diferentes, pero en las que sean posibles la paz, la justicia y la armonía.

35. Nuestra misión como Jesuitas y como miembros de la Familia Ignaciana es proclamar que "la fe que hace justicia[...] entabla diálogo con otras tradicio nes, [...y] evangeliza la culturä' (CG 34, d.2, n. 21). Pero no podemos ser leales a esta misión a menos que hagamos frente a los retos que nos plantean los diversos tipos de violencia, conflictos armados y guerras, que a veces hacen que sea imposible ejercer nuestra misión y llevar a cabo los fines a los que estamos llamados. Los conflictos actuales bloquean los cambios necesarios en el camino hacia la justicia, entorpecen las condiciones para un diálogo fructífero con otras tradiciones religiosas y generan tensiones y dilemas en un proceso más profundo de inculturación. Como consecuencia, el trabajo hacia la paz se convierte en un elemento esencial de nuestra misión.

\section{Algunas elecciones estratégicas}

36. Durante el proceso de nuestro discernimiento comunitario hemos percibido algunas líneas maestras que puedan orientar nuestra participación en la trasformación del conflicto hacia una paz sostenible. No es nuestro objetivo proponer y detallar todas las opciones concretas que tendremos que elegir en nuestro camino. Más bien queremos destacar algunas orien taciones u opciones que puedan ayudarnos a avanzar en un camino más comprometido, participando más profundamente en la estrategia divina al servicio de una humanidad sumida en la violencia, como nos enseña la vida de Jesús de Nazaret. Nuestra más profunda orientación deber ser la esperanza hacia una paz universal e integral. Sabemos que en este esfuerzo vamos a involucrarnos en un proceso que sane las heridas y reconcilie a las personas, porque vivimos en un mundo violento que contrasta dolorosamente con nuestras visiones de paz. En este sentido, lo que exponemos en adelante, son temas de discernimiento que se dirigen a miembros de la Familia Jesuítica, involucrados en el servicio a la paz en medio de situaciones de violencia. Ya que discernimiento significa "proceso", las posiciones que se exponen a continuación no deben considerarse cerradas. 
Una opción por la lucha no violenta a favor de la justicia

37. Aunque la idea de no violencia es compleja y requiere un análisis matizado en cada situación concreta, apunta al deseo de trabajar por la paz en forma que refleje el objetivo, es decir, la justicia y la paz. Tendremos que poner un cuidado especial en no quedar atrapados en lógicas de violencia del tipo que sea. La violencia estructural puede ser particularmente crítica. La acción no violenta debería ser entendida desde el punto de vista de un ansia de paz en medio de situaciones de violencia. No es ciertamente una forma de pasividad de cara a la injusticia. De hecho, puede haber momentos en que se requiera el uso proporcionado de la fuerza física, precisamente para contraatacar la injusticia o la violencia (situaciones de opresión o de violación masiva de derechos humanos, o de genocidio). Estamos llamados a un proceso de aprendizaje en la línea de lo que el Papa Juan Pablo II escribió en Centesimus Annus: "Que el hombre aprenda cómo luchar por la justicia sin violencia" (CA, III, 23)

Una opción por aquellos que sufren violencia, guerra e injusticia

38. Al luchar por una paz sostenible en medio de situaciones violentas afrontamos la cuestión de dónde estamos y con quién nos aliamos prefe rentemente: ¿quiénes son nuestros amigos? Este es el tema planteado por nuestra opción por aquellos que sufren violencia, injusticia y guerra. Los que sufren, tocan nuestros corazones cuando oímos sus gritos y escucha mos sus historias. Junto con ellos y en un proceso cuidadoso de escucha y discernimiento, creemos que Dios nos dará la gracia de descubrir cami nos originales y creativos para abordar y enfocar la violencia a la que nos enfrentamos juntos. Tendremos cuidado, en las situaciones de violencia, de no caer en la tentación de un victimismo fácil y de una demonización o polarización aún más fáciles. Es por tanto que serán necesarios análisis metódicos y precisos.

\section{Una opción por Identidades Inclusivas e Interdependientes}

39. La violencia, los conflictos y las guerras suelen provocar problemas de identidad. La construcción de identidades no es una actividad inocente en un contexto de violencia, y estamos convencidos de que en todas las situaciones concretas existe la necesidad de un proceso de discernimiento hacia 
la construcción y elaboración de identidades inclusivas, interconectadas e interdependientes, que en sus interacciones polifacéticas promuevan un es fuerzo por la paz. Será especialmente importante no enredarse en prejuicios y estereotipos, no imponer identidades negativas o inferiores a los demás.

\section{Opción por las mujeres}

40. En el contexto de los conflictos contemporáneos merecen especial atención aquellos que más sufren las consecuencias de la violencia: las mu jeres. Tenemos que aprender a ver con mayor profundidad el potencial de la mujer para la construcción de una paz sostenible. Los niños y ancianos sufren también la guerra de forma desproporcionada, y en nuestros minis terios debemos preocuparnos especialmente por su sufrimiento.

\section{Opción por el apoyo a culturas amenazadas}

41. Cada vez se hace más hincapié en el papel de las culturas en la tras formación del conflicto y en la paz sostenible. Los pueblos indígenas han desarrollado en sus tradiciones estrategias para ello que nosotros tendemos a pasar por alto. Será importante, por lo tanto, afirmar, apoyar e incluso defender la dignidad y el derecho a existir de las culturas locales, mediante alianzas constructivas que sean propicias para procesos mutuos de aprendizaje precisamente en la construcción de una paz sostenible.

\section{Opción por un buen gobierno}

42. Muchos de los conflictos y la violencia de hoy tienen su origen en la corrupción y en el mal gobierno, en medio de la ilegalidad o del abuso de la ley. La corrupción y las situaciones post-conflicto pueden socavar los esfuerzos previos por la paz. Por eso consideramos parte esencial de la defensa de la paz el prestar atención al buen gobierno y a la construcción de instituciones nacionales e internacionales más efectivas, en la línea que sugería Juan XXIII en Pacem in Terris Ponemos el énfasis en un gobierno justo y una ley justa, en la transparencia y en la participación. Como contrapeso a los abusos legales y a los gobiernos corruptos, esto conlleva la voluntad de establecer alianzas con los que constituyen la sociedad civil (a nivel nacional e internacional) al servicio de la paz mundial. Este enfoque exige personas expertas y una profunda espiritualidad integradora: la capacidad de escuchar las voces y 
los gritos de los que sufren abusos, y un trabajo meticuloso de incidencia (advocacy) a nivel institucional.

\section{Opción por la solidaridad global}

43. Hemos visto que la globalización es un factor importante cuando tratamos de analizar hoy las realidades de violencia y paz, y que puede convertirse en fuente de nuevas formas de violencia e injusticia, o bien intensificar las formas existentes de violencia e injusticia. Nos hemos dado cuenta de que es necesario promover una solidaridad global y una evolución en la solidaridad (Juan Pablo II). Nos sentimos llamados a desarrollar aún más la creciente interconexión global dentro de una red de responsabilidad y solidaridad mutuas. 